\title{
PARA UMA EDUCAÇÃO AMBIENTAL TRANSFORMADORA: UMA EXPERIÊNCIA PEDAGÓGICA NO CURSO DE PEDAGOGIA/FACED/UFAM ${ }^{1}$
}

\author{
Lucas Antunes Furtado ${ }^{2}$ \\ Jucinôra Venâncio de Souza Araújo ${ }^{3}$
}

\section{Resumo}

Este trabalho é um relato de experiência sobre uma atividade desenvolvida na disciplina de educação ambiental por acadêmicos dos cursos de Pedagogia da Faculdade de Educação da Universidade Federal do Amazonas junto a estudantes do Núcleo de Desenvolvimento Familiar/NDF/Adcam. Primeiramente foram realizadas entrevistas semiestruturadas com os professores da instituição a fim de diagnosticar problemas no que tange à questão ambiental, sendo detectado o desconhecimento dos alunos quanto às formas de reaproveitar/reutilizar materiais sólidos. Posteriormente foi realizada uma oficina pedagógica por meio de atividades lúdicas e interativas com os alunos. Acreditamos que a experiência vivenciada pelos acadêmicos, pelos professores e pelos alunos, a partir de suas avaliações positivas quanto aos conhecimentos adquiridos na oficina, contribuíram significativamente para a superação de um pensamento fragmentado da realidade, na busca de pensar a questão ambiental de forma complexa, crítica e transformadora.

Palavras-Chave: Educação; Educação Ambiental; Práxis Pedagógica.

\section{INTRODUÇÃO}

A questão da educação ambiental está em pauta nas discussões em vários segmentos da sociedade, pois remete a processos históricos, sociais, políticos, econômicos e culturais. Todas essas questões estão interligadas, no sentido de que as ações que ocorrem em tais campos sempre repercutem sobre o indivíduo em sua relação com a sociedade, ou seja, com o ambiente ao qual está inserido.

Nesse sentido, o relato de experiência pedagógica aqui proposta buscou contribuir com a formação crítica dos/as acadêmicos/as sobre educação ambiental no contexto amazônico. Educar para uma consciência crítica sobre a questão

\footnotetext{
${ }^{1}$ Fundação de Amparo à Pesquisa do Estado do Amazonas/Fapeam

2 Programa de Pós-Graduação em Educação/Ppge/Faced da Universidade Federal do Amazonas/Ufam - prof.lucasfurtado@gmail.com

3 jucinora12@yahoo.com.br
} 
ambiental requer uma postura de emancipação cognitiva contribuindo para uma leitura crítica do mundo.

Assim, o presente relato de experiência está organizado em três partes. Primeiramente, discutiremos alguns conceitos e desafios referentes à questão da educação ambiental. Em seguida, contextualizaremos a experiência pedagógica desenvolvida na disciplina de educação ambiental com os acadêmicos dos cursos de Pedagogia da Faculdade de Educação/Faced da Universidade Federal do Amazonas/Ufam. E por último, tecemos algumas considerações sobre os conceitos da questão ambiental relacionada com a prática pedagógica que contribuíram para uma reflexão crítica sobre o meio ambiente e o papel de cada sujeito no desenvolvimento de uma consciência ambiental.

\section{A QUESTÃO DA EDUCAÇÃO AMBIENTAL: CONCEITOS E PERSPECTIVAS}

Discutir a questão da educação ambiental é, sem dúvida, trilhar um caminho complexo e conflituoso. Complexo porque a questão envolve múltiplos elementos nas dimensões sociais, históricas, políticas, culturais e econômicas na tentativa de empreender uma análise coerente sobre o cenário socioambiental. Conflituoso por se tratar de uma questão que envolve outras áreas do conhecimento humano, tornando-se um "campo minado", pois as formas de perceber e pensar o mundo/realidade são diversas, e cada área do conhecimento, tende a tecer suas considerações sem um dialogar sobre tal questão.

Tal diagnóstico caracteriza-se como uma crise da racionalidade dominante, como explica Herique Leff (2007); "La cuestión ambiental, más que una problemática ecológica, es una crisis del pensamiento y del entendimento, de la ontología y de la epistemología con las que la civilización occidental ha comprendido el ser, a los entes y a las cosas" (p. 47). Significa dizer que a racionalidade científica tem sido desenvolvida de forma fragmentada, rígida, e excludente descaracterizando as relações entre os processos da vida humana.

Em consonância com Leff, Raynaut (2004) afirma que:

Estamos em um momento crítico do desenvolvimento do pensamento humano. Ao mesmo tempo assistimos ao triunfo da ciência como instrumento de mudança de nossa existência individual e coletiva e ao questionamento do papel da mesma, junto com dúvidas sobre a natureza do conhecimento que ela traz. Muitas certezas estabelecidas sobre a herança 
do positivismo científico e da utopia do progresso e da modernidade vacilam (p. 22).

Tais "certezas científicas", herdadas do pensamento moderno, "vacilam" na tentativa de encontrar soluções totalitárias para as questões socioambientais, segundo Santos (2010): “(...) falar-se de um modelo global de racionalidade científica que admite variedade interna, mas que se distingue e defende, por via de fronteiras ostensivas e ostensivamente policiadas (...)" (p. 21). Se os meios ou formas de produção de conhecimentos significativos para contribuir com a humanidade são frutos de processos "ostensivamente policiados" podemos considerar que precisamos superar tal perspectiva, pois como Santos (2010) afirma: “(...) A razão por que privilegiamos hoje uma forma de conhecimento assente na previsão e no controle dos fenômenos nada tem de científico. É um juízo de valor (...)" (p. 83-84).

Assim, fica claro que para discutir a questão da educação ambiental não poderemos trilhar um único caminho epistemológico. Precisamos beber de outras fontes e se nutrir, epistemologicamente, de um banquete de conhecimentos inteligíveis. A partir dessa perspectiva, poderemos empreender uma análise sobre os conceitos que giram em torno da educação ambiental.

Tozoni-Reis (2006) explica que; “(...) a (im)possibilidade de educar fora do ambiente, fora de um determinado espaço biofísico, social e histórico. Por consideramos impossível realizar qualquer proposta educativa sem incluir a reflexão sobre a relação que temos com o ambiente em que vivemos (...)" (p. 7) e, concomitantemente, Gadotti (2007) afirma; “(...) que a educação não está separada do meio ambiente (...)" (p. 77). Assim, devemos problematizar e qualificar os conceitos de educação ambiental a partir dos princípios éticos, políticos e pedagógicos.

(...) a Educação Ambiental é Educação e que a introdução do termo ambiental propõe o resgate do que parecia esquecido na Educação moderna: o ambiente. Grün (1996) identifica este esquecimento como uma das "áreas de silêncio" da Educação moderna, que estabeleceu-se sob a organização da sociedade capitalista industrial e, desde sua origem, esteve a serviço deste projeto social, econômico e político (...) (TOZONI-REIS, 2006, p. 7).

Partindo do pressuposto de que a "Educação Ambiental é Educação", devemos então pensar em como produzir os meios de acesso aos processos 
socioeducativos sensíveis à questão ambiental levando em consideração as indicações de Floriani (2007) sobre a educação; “(...) essa não pode ser transmitida de fora do sujeito, ela é o próprio caminho do sujeito, que se faz sujeito no caminho (...), que reflete esteticamente sobre as intermitências do sujeito humano, acossado pelo interativo de continuar" (p. 506).

Perseguindo a ideia de continuação do sujeito podemos considerar que a educação ambiental é um processo de aprendizagem significativa, contínua, prudente, expandindo seus horizontes conceituais e evocando o direito e o dever do ser humano, como um cidadão responsável, a contribuir com a transformação socioambiental. Pode ser compreendida com uma estratégia para construir um cenário mais humano, socialmente justo e equilibrado ecologicamente. A educação ambiental, segundo Tozoni-Reis (2006); “(...) é uma educação política, democrática, libertadora e transformadora (...)" (p. 10).

Portanto, o homem que intervem sobre a sociedade, sobre a cultura, sobre a natureza, como cidadão ou profissional, o faz preparado pelas orientações que sua formação humana, sua socialização, sua educação, enfim, sua educação ambiental, permitem e determinam e, assim, sucessivamente, ad infinitum (TASSARA, 2007, p. 444).

A educação ambiental não é neutra. É política no sentido de construção das capacidades necessárias para enveredar e levantar o estandarte da transformação social, convocando a participação dos sujeitos, diante do meio em que vivemos. Segundo Floriani (2007); "O sujeito não é apenas o portador do sofrimento ou da percepção do mundo. É, ao mesmo tempo, seu criador e facilitador/obstaculizador. Desde uma perspectiva de criação pelo conhecer, o sujeito é quem entretém uma relação de convivência e de interatividade com o objeto" (p. 507).

Nesse sentido, o sujeito por si só não irá se descobrir como um cidadão ambientalmente responsável. Faz-se necessário um projeto de formação que verdadeiramente esteja para contribuir com a formação de sujeitos com consciência política e sensível pela causa da educação ambiental. A formação de sujeitos críticos e responsáveis "é uma ação política intencional, um processo educacional intencional e que, portanto, necessita de sistematização pedagógica e metodológica" (TOZONI-REIS, 2006, p. 13). E para isso, Leff (2007) nos explica que a formação do saber ambiental: 
(...) implica desconstruir lo pensado - del pensamiento disciplinario, simplificador, unitário - para pensar lo por pensar, para desentrañar lo má entrañable de nuestras últimas certezas y a cuestionar el edificio de la ciência. ... la racionalidad ambiental se sostiene en el propósito de refundamentar el saber sobre el mundo que vivemos desde lo pensado en la historia y el deseo de vida que se proyecta hacia la construcción de futuros inéditos a través del pensamiento y la acción social (p. 51).

No trabalho de construir "futuros inéditos a través del pensamiento y la acción social", Tassara (2007) nos explica que tais projetos socioambientais viriam; "compactar-se (...) e difundirem seus efeitos, sob forma de mudanças cognitivas, afetivas e atitudinais, influenciando a produção da consciência ambiental capacidade de emitir juízos críticos originais sobre o cotidiano" (p. 447), e continua:

Tais intervenções (...) objetivando a mudança estrutural da vida social,
condição que se apresenta como necessária para a transformação
ambiental conforme caracterizada. Somente dessa maneira seria possível o
exercício de influências democratizadoras na definição e aproximação
gradativa a ideia compartilhados de bem comum, vindo a refletir sobre o
delineamento participativo de formas de organização humana respeitadoras
dos momentos-imagens de desejabilidade e de sustentabilidade sócio-
política-ambiental (TASSARA, 2007, p. 447).

Isso significa dizer que, a educação ambiental é de uma escolha políticoeducativa norteada pela concepção de que existimos em um espaço ecologicamente em crise e desigual fruto das escolhas históricas propedêuticas. A educação ambiental pode ser pensada, segundo Tozoni-Reis (2006); “(...) como um processo político de apropriação crítica e reflexiva de conhecimentos, atitudes, valores e comportamentos que têm como objetivo a construção de uma sociedade sustentável do ponto de vista ambiental e social” (p. 11).

Aqui a educação ambiental é caracterizada como um processo socioeducativo de instrumentalização do sujeito para a prática social em prol da construção e manutenção de condições de vida digna e prudente. Podemos dizer que as ideias educativas, segundo Tozoni-Reis (2006); “(...) emergem dessa concepção das relações sociais que dizem respeito à formação humana. O desenvolvimento pleno dos sujeitos, a busca do homem omnilateral e o processo de humanização, que é histórico, concreto e dialético, expresso pela sua prática social (...)" (p. 12).

A educação ambiental está sendo construída em um processo contínuo e dinâmico entre os conhecimentos e as relações sociais. Nesse processo de construção de sentidos e significados para a educação ambiental, percebemos que emerge um paradigma socioeducativo que tem como base princípios ético-político- 
pedagógicos responsáveis por humanizar o ser humano em relação à sociedade e à natureza. Dessa forma podemos dizer que "a gênese do processo educativo ambiental é 0 movimento de fazer-se plenamente humano pela apropriação/transmissão crítica e transformadora da totalidade histórica e concreta da vida dos homens no ambiente" (TOZONI-REIS, 2004).

\section{OFICINA PEDAGÓGICA: ETAPAS E DESENVOLVIMENTO}

Contamos com a participação dos acadêmicos dos cursos de Pedagogia que cursaram a disciplina de educação ambiental no segundo semestre de 2014, no período de setembro a fevereiro de 2015, oferecido pela Faculdade de Educação/Faced da Universidade Federal do Amazonas/Ufam e, com os/as professores/as e alunos/as do Núcleo de Desenvolvimento Familiar/NDF da Associação para o Desenvolvimento Coesivo da Amazônia/Adcam.

A ideia de planejar uma oficina pedagógica socioambiental desenvolvida pelos/as acadêmicos/as surgiu a partir dos diálogos significativos empreendidos em sala de aula sobre a questão da educação ambiental. A preocupação dos/as acadêmicos/as, inicialmente, era transformar os conceitos sobre a questão ambiental em uma prática pedagógica que beneficiaria um público específico.

Diante dessa situação, iniciamos uma consulta sobre as formas e as possibilidades de pensar e executar a oficina pedagógica. No primeiro momento, identificamos uma instituição que trabalha com crianças e jovens em risco social e empreendemos uma visita para realizar um diagnóstico participativo. Os/as acadêmicos/as realizaram uma entrevista semiestruturada com alguns professores do Núcleo de Desenvolvimento Familiar/NDF/Adcam com o objetivo de identificar um problema que envolvesse a questão da educação ambiental e que, posteriormente, possibilitaria planejar uma oficina pedagógica para atender a necessidade dos/as alunos/as, contribuindo para amenização dos entraves identificados.

No segundo momento consultamos, a partir das informações coletadas através das entrevistas com os/as professores/as, sobre os problemas existentes na instituição que envolve a questão da educação ambiental. Fruto da análise das entrevistas ficou evidente que os/as alunos/as do NDF/Adcam desconheciam formas criativas para reaproveitar/reutilizar os materiais sólidos que os mesmos utilizavam. 
Assim, os/as acadêmicos/as, produziram a oficina pedagógica com o objetivo de ensinar como reaproveitar/reutilizar os materiais sólidos existentes no cotidiano.

No terceiro momento, após inúmeras consultas e reflexões, foi realizada a oficina pedagógica que contou com atividades lúdicas e interativas com a duração de três horas para um público de 25 alunos. As sequências das atividades realizadas em cada etapa são apresentadas a seguir:

1' Etapa: Apresentação do grupo. Cada acadêmico se apresentou e deu as boas vindas aos alunos do NDF/Adcam.

Dinâmica de Interação: "Eu sou...". A dinâmica deu-se, inicialmente, com a distribuição de cartões com fotos e o perfil de pessoas que lutam e/ou lutaram pela questão ambiental. Cada participante leu seu cartão e se apresentou informando seu nome, idade e seu pensamento sobre o meio ambiente.

Exibição do Vídeo: "O Homem" produzido por Steve Cutts. O vídeo tem a duração de quatro minutos e mostra de forma bem lúdica o que o homem é capaz de fazer com o meio ambiente para satisfazer suas necessidades.

Roda de Conversa: Os/as acadêmicos/as perguntaram para os/as alunos/as quais foram suas impressões sobre o vídeo? Assim, os/as alunos/as deram suas opiniões.

2a Etapa: Oficina Pedagógica. Tutorial de reaproveitamento/reutilização de materiais sólidos. Primeira atividade "Porta Lápis" com os seguintes materiais, latas de leite, tinta guache ou de tecido, prato plástico e pistola com refil de cola quente. Segunda atividade "Vaso de Flor" com os seguintes materiais; latas de leite, tinta guache ou de tecido, barbante, prato plástico e pistola com refil de cola quente. E por último, "Lustre" com os seguintes materiais; balão, tinta guache, cola branca e pincel colorido.

3몰 Etapa: Avaliação Final. Os/as alunos/as expressaram suas conspirações sobre a questão da educação ambiental, fazendo a relação do vídeo com a oficina pedagógica e, finalizando com uma avaliação da oficina. 


\section{CONSIDERAÇÕES FINAIS}

Acreditamos que a experiência socioeducativa vivenciada pelos acadêmicos do curso de Pedagogia da Faculdade de Educação/Faced/Ufam, pelos professores e pelos alunos do Núcleo de Desenvolvimento Familiar/Ndf/Adcam, a partir de suas avaliações positivas, coletadas e analisadas por intermédio das entrevistas semiestruturadas e questionários qualitativos, quanto aos conhecimentos construídos e compreendidos durante o desenvolvimento da oficina pedagógica contribuíram significativamente para a superação de um pensamento fragmentado sobre à questão ambiental.

Tal situação suscitou a necessidade de promover mais espaços pedagógicos para promover discussões sensíveis à questão ambiental, proporcionando perceber a urgente necessidade de (re)pensar os processos de formação dos/as professores/as para uma perspectiva crítica, porque estes serão os formadores de opiniões das novas gerações de cidadãos, no sentido de que possam fazer uma leitura crítica de sua realidade, de pensar as questões ambientais de maneira complexa e interligada aos fatores sociais, econômicos, culturais, políticos etc., buscando adquirir modos de pensar e agir que visem uma melhor qualidade de vida para a sociedade.

Nesse processo de (re)construção de sentidos e significados para a educação ambiental, percebemos que surge um paradigma socioeducativo que tem como base princípios ético-político-pedagógicos responsáveis por humanizar o ser humano em relação à sociedade e à natureza. Dessa forma podemos dizer que "a gênese do processo educativo ambiental é o movimento de fazer-se plenamente humano pela apropriação/transmissão crítica e transformadora da totalidade histórica e concreta da vida dos homens no ambiente" (TOZONI-REIS, 2004).

\section{REFERÊNCIAS}

FLORIANI, Dimas. Pensamento complexo, interdisciplinaridade e educação ambiental: Bases para uma epistemologia sócio-ambiental emergente. Red de Formación Ambiental para América Latina y el Caribe. 01 Ed. 2007.

LEFF, Enrique. Complejidad, racionalidade ambiental y diálogo de saberes: Hacia uma pedagogia ambiental. Red de Formación Ambiental para América Latina y el Caribe. 01 Ed. 2007. 
da Alta Paulista

RAYNAUT, Claude. Meio ambiente e desenvolvimento: Construindo um novo campo do saber a partir da perspectiva interdisciplinar. Desenvolvimento e Meio Ambiente, $n^{\circ} 10$, p. 21-32. Jul/dez. Editora UFPR.

SANTOS, Boaventura Sousa. Um discurso sobre as ciências. - 07 Ed. - São Paulo: Cortez, 2010. TASSARA, Eda Terezinha de O. Educação ambiental e universidade: Ensino, pesquisa e extensão. Red de Formación Ambiental para América Latina y el Caribe. 01 Ed. 2007.

TOZONI-REIS, Marília Freitas de C. (Re)pensando a educação ambiental. In: V Congresso lberoAmericano de Educação Ambiental, 2006, Joinville-SC.

TOZONI-REIS, Marília Freitas de C. Educação ambiental: Natureza, razão e história. Campinas: Autores Associados, 2004. 